\title{
READINGS IN LAMENTATIONS:
}

\section{ESSAYS ON THE TEXT, INTERPRETATION AND RECEPTION OF LAMENTATIONS}

$\mathrm{T}$ The collection of six essays on the book of Lamentations presented here are the outcome of an initiative begun in 2011 to gain the insights and perspectives of scholars in various areas of specialization on the "text" and "interpretation" of Lamentations. This initiative forms part of a larger research project that has the text and interpretation of Lamentations as its focal points. The contributors were invited to understand the two focal points as broadly or narrowly as they wished and to concentrate their efforts on an aspect of Lamentations research, a theme or feature of the book, a verse/verses/chapter(s) from the book, one or more of its textual representatives, or the book's Wirkungsgeschichte. The results of the invitation are two essays on the textual representatives of Lamentations (Van Rooy [the ancient versions] and Kotzé [the Masoretic text and a Qumran manuscript]), an investigation of the theme of maternal cannibalism in Lamentations 2:20 and 4:10 (Bosman), an essay that comments on the absence/presence of YHWH in Lamentations 3 from the perspective of a specific type of Derridean philosophy of history/literature, namely hauntology (Gericke), and two contributions that touch on the reception of Lamentations in different periods of time and bodies of tradition (Jonker [rabbinic literature]; Naudé and Miller-Naudé [English Bible translations, especially the King James Bible]).

Although extremely diverse in theme and approach, the six essays share at least two characteristics. First, all of the contributions engage in topics that are either neglected in Lamentations research, or have received only little or no attention in existing scholarship. Secondly, a close reading of the essays will reveal that each one makes a novel contribution to the study of the text, interpretation or reception of Lamentations.

I wish to express my gratitude to Professors Hendrik Bosman, Louis Jonker, Cynthia Miller-Naudé, Jacobus Naudé and Herrie van Rooy, as well as to Dr Jaco Gericke, for their willingness to contribute to this collection and for all the time and hard work they put into their essays. As a first reader I was often pleasantly surprised, sometimes confused, but always delighted by their contributions. I hope that other readers will learn as much from them as I have. I also wish to thank the editors of Scriptura, especially Prof Bosman, for allowing the essays to be published as a collection in their journal. 